used to define phenotypes of affective disorders. Part 3 considers how longitudinal studies can be informative, with examples drawn from studies on alcohol use and attention-deficit hyperactivity disorder. The final part, 'Exploring alternatives', brings together four authors who have interesting ideas about how genetic studies may inform the definition of phenotypes.

In 1970, Sam Guze \& Eli Robins wrote a seminal and much-quoted paper on the indirect validation of phenotypes in psychiatry. They were also the first to apply an operational approach to defining psychopathology. Since then, there has been much effort but little real progress, and ideas about defining psychopathology have not really advanced. However, this book provides an optimistic view of the future. The technological advances in neuroimaging and genetics hold considerable promise for new ways of thinking about phenotypes. This publication provides a starting point for all who wish to take up the challenge of defining psychopathology in the 21 st century.

Robins, E. \& Guze, S. B. (1970) Establishment of diagnostic validity in psychiatric illness: its application to schizophrenia. American Journal of Psychiatry, 126, 983-987.

Anne Farmer Professor of Psychiatric Nosology, MRC Social, Genetic and Developmental Psychiatry Research Centre, Institute of Psychiatry, De Crespigny Park, London SE5 8AF, UK

\section{Measuring Mental Health Needs (2nd edn)}

Edited by GrahamThornicroft.

London: Gaskell. 200 I. 524 pp. 35.00 (pb).

ISBN I 90I242609

The second edition of this excellent resource book is very welcome. It is now 10 years since the first edition and during that time the concept of measuring needs in mental health has become increasingly part of the planning process and research agenda. Like all edited works there is some patchiness and a degree of overlap between some of the chapters. One or two chapters seem to have been included more for completeness of the volume and their authors have given a 'needs-measurement' spin to what they normally write. This is inevitable in a volume of this scope, and

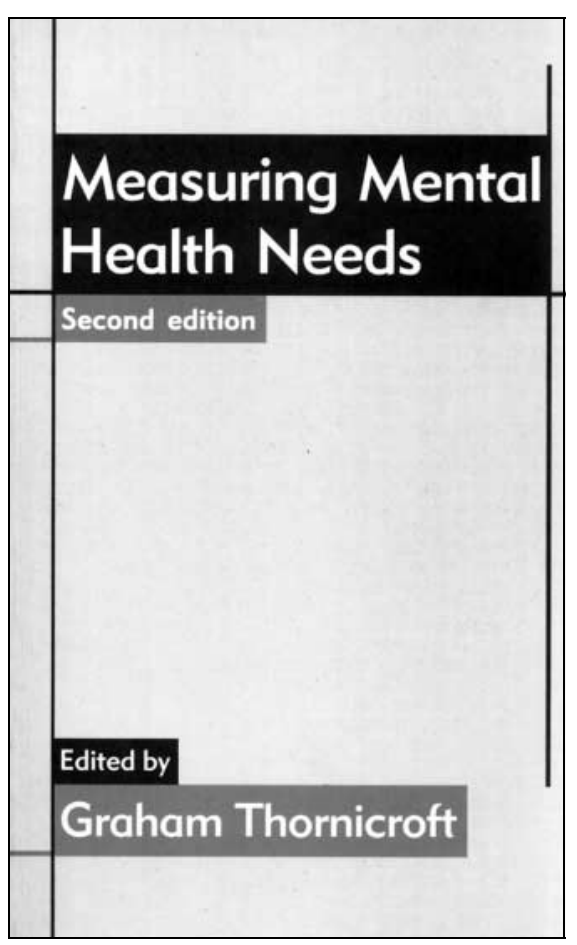

overall the tone of the work is both scholarly and practical and the standard very high.

This is a reference book rather than a textbook with which to learn the business. Whatever your current preoccupation composing a research proposal, conducting an option appraisal for a service development, commissioning services, etc. - there are chapters here relevant to your thinking. In this context, the occasional repetitiveness is a positive advantage as it helps give depth to understanding. The different perspectives in the book stimulate thinking and give a sense of dialogue rather than a dusty tome. For example, in Gregoire's chapter on needs assessments for rural mental health services you can learn as much about the complexity of defining 'rural' as about mental health needs in rural areas. Complex ethical issues are also touched on: Kuipers, for example, explores the needs of carers.

I would have liked a bit more theory, in particular the status of needs as a concept. The sheer volume of research into individual needs (paralleled by the rapidly growing, and now multilingual, Camberwell Assessment of Needs family) often obscures the fact that some of us have genuine concerns about the meaningfulness of the concept. When considering an individual patient is it really more useful to talk of needs that can or cannot be met rather than illnesses and problems that can or cannot be addressed by treatments or interventions? The daily experience of shoe-horning 'diagnosis and treatment' into the Care Programme Approach's required 'needs and interventions' gives rise to some scepticism.

This is, however, a small criticism of an excellent book. It is thorough, weighty yet accessible, and lives up to the blurb on its cover in that it 'describes clearly the different approaches that can be taken to these vital questions'. There is something for everyone here. It is well worth its second edition and well worth the price.

Tom Burns Head of Social and Community Psychiatry, Department of General Psychiatry, St George's Hospital Medical School, Jenner Wing, Cranmer Terrace, London SWI7 ORE, UK

\section{Introducing Cognitive Analytic Therapy. Principles and Practice}

By Anthony Ryle \& Ian B. Kerr. Chichester: John Wiley \& Sons. 2002.265 pp. $€ 19.99$ (pb). ISBN 0 47I 892734

Reading this book brought to mind a sobering experience from my youth. In 1966, I visited a psychotherapy institute in Leningrad (now St Petersburg). Its doctors said they used 'Pavlovian' psychotherapy. How did they do this? They admitted

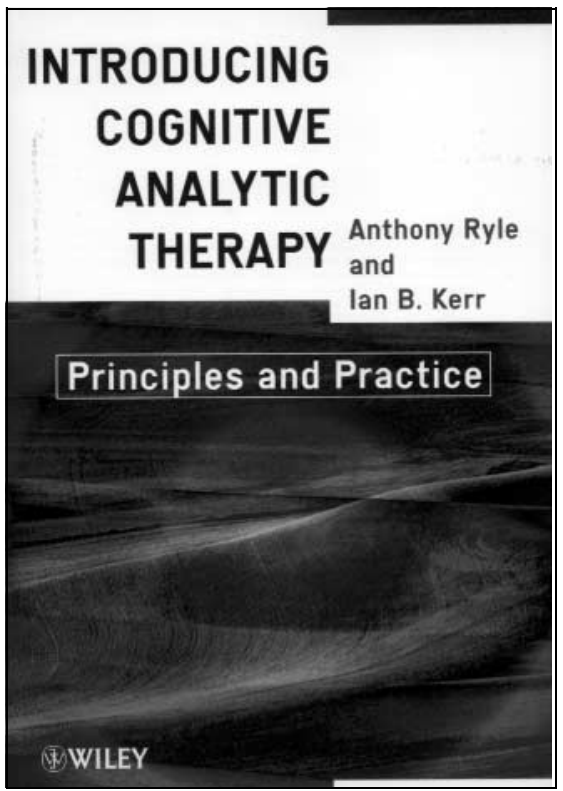


patients, took a detailed history of their upbringing and showed them how current maladaptive behaviours grew out of earlier forms of interaction with family and others which needed revision to become more appropriate to current circumstances. Western psychotherapists using a similar approach might have been surprised to hear that Pavlov was its progenitor. Now Ryle $\&$ Kerr see it as part of cognitive analytic therapy (CAT), which takes about 16 sessions. Together with the patient, the therapist writes a reformulation letter that sets out aims in therapy. The patient selfmonitors, with the help of a diary, to spot problems as they arise and try to revise them, and rates target problems. The patient and therapist exchange goodbye letters at the penultimate or last session to review what has been achieved or remains to be done, and follow-up is arranged.

Case examples show how CAT assessment is done and reformulation letters and diagrams are constructed. Its use of a goal-oriented approach, diary-keeping, self-ratings and collaboration with the patient overlaps with the practice of behavioural and cognitive therapists. However, a case history of CAT in a patient with obsessive-compulsive rituals (pp.138-144) highlights how CAT differs from behaviour therapy by exposure and ritual prevention: the 'target problem' procedures did not mention the rituals, the post-treatment rating of improvement did not say whether or not rituals reduced, and a mean of 16 sessions of 'brief' CAT exceeds the 9 sessions usual with face-to-face behavioural therapy, let alone the single hour of clinician contact needed with computeraided behavioural therapy. The authors acknowledge the paucity of controlled trials of CAT. The aim of CAT in early dementia seemed unclear (p. 156).

The authors say that CAT derives its ideas from evolutionary psychology, genetics, developmental neurobiology and psychology, and uses a 'Vygotskian perspective' regarding 'sign mediation', 'Bakhtinian concepts of the dialogic self' and 'Kellyian personal construct therapy, cognitive therapy and psychoanalytic object relations theory'. These supposed roots remind one of the historian's warning of 'idols of origin'.

A would-be practitioner might learn more from the book's case illustrations than its turgid theoretical digressions, replete with redundant argot. We need not have heard of Vygotsky to know about meaning, intention and signs, or of Bakhtin to know that we are social beings.

The case histories give an idea of what CAT is about, but the book testifies to the long journey ahead before psychotherapy can reach the authors' laudable goal of a lucid language, method and evidence-base shared by all practitioners.

Isaac Marks Emeritus Professor, Institute of Psychiatry, King's College London, and Senior Research Investigator and Honorary Consultant Psychiatrist, Department of Psychiatry, Faculty of Medicine, Imperial College School of Science, Technology \& Medicine, 303 North End Road, London WI4 9NS, UK

\section{Confidentiality and Mental Health}

Edited by Christopher Cordess. London: Jessica Kingsley. 2000. 192 pp. Ł16.95 (pb). ISBN I 853028606

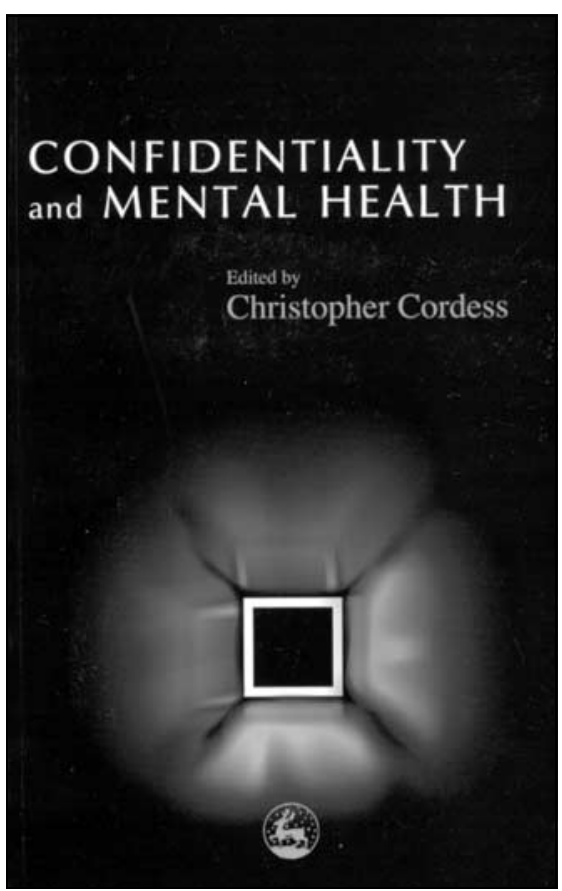

As I write this review, British soldiers are appearing anonymously behind screens in courts to discuss the Bloody Sunday shootings of 1972, and the jury reads Princess Diana's letters in silence so as not to disclose their secrets. In court, a journalist has been ordered to divulge his source of information from Ian Brady's confidential medical records. Jeffrey Archer has named inmates he encountered in prison, and has been punished for this. Confidentiality and disclosure - is always in the news.

Once upon a time, it may have been straightforward to determine the boundaries of confidentiality. That was before the GMC, BMA, MRC and Royal College of Psychiatrists issued guidelines. The report of the Caldicott Committee in 1997, the Human Rights Act 1988 and the Data Protection Act 1998 have all sought to reduce the unnecessary flow of information, but multi-agency public protection panels and the National Service Framework demand communication with others. In recent years, it has become difficult to know what a secret is - or should be. It is easy to be paralysed by uncertainty about whether to disclose information or to maintain secrecy.

This book sprang from a conference in Sheffield in 1998, and thus has the strengths and weaknesses of conference proceedings. It is inconsistent and variable in style. It will date. Nevertheless, it is far more helpful than the plethora of guidelines issued by the acronymic organisations above. Rather than laying down graven principles, this volume seeks out the interstices of understood practice. Consequently, its focus is on practical difficulties rather than ensuring that one can adhere to the law. The authors attack the subject from a number of angles and are pleasingly multi-disciplinary.

The specifics of this book are the milieux in which psychiatrists are challenged by the dilemmas of confidentiality and its mandated breach, in either private or public interest. The volume covers children, psychoanalysis, prisons and research. Approaches are variably psychodynamic, ethical, legal and clinical. The multi-author approach works well in expounding the different needs of specific populations of patients. Some chapters shine: Fulford, Szmukler \& Holloway, Bailey and Kaul are particularly provocative and helpful. In discussions about, for instance, whether to disclose confessions of paedophilia and risk the therapeutic relationship, this book is instrumental in laying bare the underlying issues. No simple guidelines could ever address the complexity of such issues.

It is unreasonable to expect that any single volume will provide a do-it-yourself guide sufficient to manage the subtle and varied situations that delineate the tension between privacy and disclosure. However, a strong approach would seek to define the 